\title{
F+0 Diuresis Renography in Infants and Children
}

\author{
David C. Wong, Monica A. Rossleigh and Robert H. Farnsworth
}

Departments of Nuclear Medicine and Urology, The Prince of Wales and Sydney Children's Hospitals, Sydney, Australia

\begin{abstract}
The purpose of this study was to evaluate the feasibility of modifying diuresis renography by the simultaneous administration of $99 \mathrm{~m}$ Tc-mercaptoacetyltriglycine (MAG3) and furosemide in the investigation of hydronephrosis and hydroureteronephrosis in infants and children. Two parameters were assessed: the
\end{abstract} diuretic response in normal kidneys and the ability of the F+0 study to differentiate between renal obstruction and nonobstruction and to identify the level of obstruction in cases of renal obstruction. Methods: Seventy-two patients (48 males, 24 females; age $2 \mathrm{~d}$ to $7 \mathrm{y}$; median age $6 \mathrm{wk}$ ) with sonographic diagnoses of hydronephrosis or hydroureteronephrosis were reviewed prospectively over a 3-y period. All patients had prior sonographic studies and micturating cystourethrography. Bladder catheterization was not routinely performed and was undertaken only if the child had suspected vesicoureteric junction (VUJ) obstruction or grade II or more vesicoureteric reflux. A weight-adjusted dose of $99 \mathrm{mTC}-\mathrm{MAG} 3$ (maximum $200 \mathrm{MBq}$, minimum $20 \mathrm{MBq}$ ) and $1 \mathrm{mg} / \mathrm{kg}$ of furosemide (maximum $40 \mathrm{mg}$ ) were administered intravenously at the same time. Posterior imaging of the kidneys and bladder was performed for $20 \mathrm{~min}$ and followed by gravity-assisted drainage or imaging after voiding. All patients were followed-up for 6-12 mo, and the final diagnoses were based on either surgery or conservative management with repeated sonography or follow-up 99mTC-MAG3 studies (or both). The results of the $F+0$ diuresis renography were then compared with the final diagnoses. Results: A renal unit was defined as a kidney and its ureter. There were 151 renal units with 1 patient having bilateral duplex kidneys, 6 patients having unilateral duplex kidneys and 1 patient having a solitary kidney. Fifty-five normal renal units and 96 abnormal renal units on the basis of sonographic findings were assessed. The furosemide clearance half-time for the 55 normal renal units was $1.3-6.3$ min (mean 3.8 $\mathrm{min}$ ). Of the 96 abnormal renal units, 53 were classified as nonobstructed and 43 were classified as obstructed. Of the 53 renal units classified as nonobstructed, there were 48 true-negative studies and 5 false-negative studies; of the 43 renal units classified as obstructed, there were 40 true-positive studies and 3 falsepositive studies. The sensitivity was $88.9 \%$, specificity was $94.1 \%$ and accuracy was $91.7 \%$. The level of obstruction, either pelviureteric junction or VUJ, was also correctly identified. Conclusion: $\mathrm{F}+0$ diuresis renography shows excellent diuretic responses in normal kidneys and is a valid method for the investigation of hydronephrosis and hydroureteronephrosis in infants and children.

\footnotetext{
Received Nov. 30, 1998; revision accepted Apr. 9, 1999.

For correspondence or reprints contact: Monica A. Rossleigh, MD, Department of Nuclear Medicine, The Prince of Wales Hospital, High St., Randwick, New South Wales 2031, Australia.
}

Key Words: diuresis renography; ${ }^{99 m}$ Tc-mercaptoacetyltriglycine; furosemide; infants

J Nucl Med 1999; 40:1805-1811

W th the widespread use of antenatal sonography during pregnancy, there has been a marked increase in the early detection of hydronephrosis and hydroureteronephrosis. This early detection has resulted in the investigation of many infants with these abnormalities $(1,2)$. Urinary tract obstruction can be located anywhere from the renal pelvis to the urethra, and, in pediatric patients, the most common site is at the pelviureteric junction (PUJ). Less commonly, the vesicoureteric junction (VUJ) or ureterocele is the site of obstruction $(3,4)$. Diuresis renography in the investigation of hydronephrosis has been shown to be reliable in the neonatal period $(5,6)$. Diuresis renography using ${ }^{99 m} \mathrm{Tc}$-mercaptoacetyltriglycine (MAG3) and diethylenetriamine pentaacetic acid has also been reported to be useful in the investigation of PUJ and VUJ obstruction in neonates and children (6-10). However, establishing venous access in infants is often difficult because the veins are small and subcutaneous fat may be prominent. In addition, some young children cannot lie relatively still for the $\mathbf{4 5} \mathrm{min}$ required for a traditional $\mathrm{F}+20$ diuresis renogram. The $\mathrm{F}+20$ diuresis renography requires an interval of 20 min between the injections of the radiopharmaceutical and the diuretic $(9-11)$, and intravenous access has to be maintained for $20 \mathrm{~min}$. The maximal effect of furosemide is $15-18 \mathrm{~min}$ after intravenous injection, justifying the alternative method of giving the diuretic $15 \mathrm{~min}$ before the radiopharmaceutical (F-15). The F-15 timing is recommended when $F+20$ results are equivocal or when renography under a state of maximal diuresis is required $(11,12)$. Again, this method involves an interval between the injections of the diuretic and radiopharmaceutical. Other investigators suggest injection of furosemide 3 min after the radiopharmaceutical $(13,14)$. Some administer the radiopharmaceutical and furosemide together. This procedure was termed $\mathrm{F}+0$ diuresis renography by $\mathrm{O}$ 'Reilly et al. (11). However, there is a paucity of literature validating this F+0 method (12). We decided to prospectively investigate modified diuresis renography in which the radiopharmaceutical and diuretic are administered together. Two parameters require validation: whether there is an adequate response in kidneys that appear normal on sonographic examination and whether renal obstruction can be differenti- 
TABLE 1

Patient Data and Results

\begin{tabular}{|c|c|c|c|c|c|c|c|}
\hline \multirow{2}{*}{$\begin{array}{l}\text { Patient } \\
\text { no. }\end{array}$} & \multirow[b]{2}{*}{ Sonography } & \multicolumn{2}{|c|}{$\begin{array}{c}\text { Scan } \\
\text { half-time (min) }\end{array}$} & \multirow{2}{*}{$\begin{array}{c}\text { Poor } \\
\text { drainage } \\
\text { with GAD }\end{array}$} & \multirow{2}{*}{$\begin{array}{l}\text { Differential } \\
\text { function } \\
\text { L/R (\%) }\end{array}$} & \multirow[b]{2}{*}{ Scan result } & \multirow{2}{*}{$\begin{array}{l}\text { Final diagnosis } \\
\text { (if different } \\
\text { from scan) }\end{array}$} \\
\hline & & $L$ & $\mathbf{R}$ & & & & \\
\hline 1 & RHN & 2.5 & $\underset{3.5 \mathrm{Im}}{\infty \mathrm{um}}$ & & $52: 48$ & $\begin{array}{l}\text { Poor function R um } \\
\text { No obs R Im }\end{array}$ & \\
\hline 2 & RHU & 2.3 & $\infty$ & $\mathbf{R}$ & $74: 26$ & R VUJO & \\
\hline 3 & RHN & 5.0 & 77.2 & & $51: 49$ & No obs $R$ & \\
\hline 4 & R HN & 3.5 & 12.7 & & $48: 52$ & No obs R & \\
\hline 5 & LHN & - & 2.3 & & $0: 100$ & No function $\mathrm{L}$ & \\
\hline 6 & LHU & $\infty$ & 2.7 & $\mathbf{L}$ & $50: 50$ & L VUJO & \\
\hline 7 & LHN & - & 3.4 & & $0: 100$ & No function $\mathrm{L}$ & \\
\hline 8 & RHN & 3.3 & 821 & $\mathbf{R}$ & $43: 51$ & R PUJO & \\
\hline 9 & LHN & - & 2.3 & & $0: 100$ & No function L & \\
\hline 10 & LHN & - & 5.3 & & $0: 100$ & No function $\mathrm{L}$ & \\
\hline 11 & Bilat HU & 16.2 & 32.5 & $\mathbf{R}$ & $49: 51$ & $\begin{array}{l}\text { No obs L } \\
\text { R VUJO }\end{array}$ & No obs $R$ \\
\hline 12 & LHN & 67 & 1.5 & $L$ & $50: 50$ & LPUJO & \\
\hline 13 & LHN & 64.5 & 1.5 & & $53: 47$ & No obs L & \\
\hline 14 & Bilat HN & $\infty$ & 25.8 & Bilat & $33: 67$ & Bilat PUJO & \\
\hline 15 & LHN & 8.8 & 3.6 & & $47: 53$ & No obs $L$ & \\
\hline 16 & LHN & 5.5 & 3.7 & & $47: 53$ & No obs L & \\
\hline 17 & Bilat HN & 16.8 & 17.1 & & $77: 23$ & No obs bilat & \\
\hline 18 & LHN & 21.6 & 5.5 & & 48:52 & No obs $L$ & \\
\hline 19 & LHN & $\infty$ & 3.5 & $L$ & $46: 54$ & LPUJO & \\
\hline 20 & LHN & 3.2 & 4.1 & & $45: 55$ & No obs L & \\
\hline 21 & RHN & 5.6 & 40.6 & R & $54: 46$ & R PUJO & No obs R \\
\hline 22 & Bilat HN & $\infty$ & $\infty$ & Bilat & $50: 50$ & Bilat PUJO & \\
\hline 23 & Bilat HN & $\begin{array}{l}\infty \mathrm{Lum} \\
\infty \mathrm{LIm}\end{array}$ & $\begin{array}{l}\infty R \text { um } \\
\infty R \text { Im }\end{array}$ & & $51: 49$ & $\begin{array}{l}\text { No obs bilat um } \\
\text { No obs bilat Im }\end{array}$ & \\
\hline 24 & RHN & 4.5 & 6.4 & & $45: 55$ & No obs $R$ & \\
\hline 25 & R HN & 5.7 & $\infty$ & $\mathbf{R}$ & $46: 54$ & R PUJO & \\
\hline 26 & LHN & $\begin{array}{l}2.8 \mathrm{Lum} \\
-\mathrm{LIm}\end{array}$ & 4.1 & & $40: 60$ & $\begin{array}{l}\text { No obs } L \text { um } \\
\text { No function L Im }\end{array}$ & \\
\hline 27 & Bilat HN & 64.5 & $\infty$ & Bilat & $49: 51$ & Bilat PUJO & \\
\hline 28 & LHN & 7.8 & 4.6 & & $36: 64$ & No obs $L$ & \\
\hline 29 & LHU & 26.1 & 3.4 & $\mathrm{~L}$ & $49: 51$ & L VUJO & No obs \\
\hline 30 & RHN & 4.8 & $\infty$ & $\mathbf{R}$ & $53: 47$ & R PUJO & \\
\hline 31 & R HN & 4.8 & $\begin{array}{l}49.4 \mathrm{um} \\
3.3 \mathrm{Im}\end{array}$ & & $51: 49$ & $\begin{array}{l}\text { Poor function R um } \\
\text { No obs } R \text { Im }\end{array}$ & \\
\hline 32 & R HN & 3.7 & 3.1 & & $48: 52$ & No obs $R$ & \\
\hline 33 & R HN & 3.1 & 4.9 & & $44: 56$ & No obs $R$ & \\
\hline 34 & LHN & 4.5 & 3.8 & & $54: 46$ & No obs $L$ & \\
\hline 35 & LHN & 4.7 & 5.4 & & $30: 70$ & $\begin{array}{l}\text { No function L um } \\
\text { No obs L Im }\end{array}$ & \\
\hline 36 & R HN & 3.1 & 16.0 & & $49: 51$ & No obs $R$ & R PUJO \\
\hline 37 & LHU & $\infty$ & 4.5 & $\mathbf{L}$ & $44: 56$ & LVUJO & \\
\hline 38 & Bilat HN & 2.3 & - & & $100: 0$ & $\begin{array}{l}\text { No obs } L \\
\text { No function } R\end{array}$ & \\
\hline 39 & LHN & 5.6 & 2.9 & & $49: 51$ & No obs $L$ & \\
\hline 40 & LHN & 3.3 & 3.5 & & $50: 50$ & No obs L & \\
\hline 41 & Bilat HN & $\infty$ & - & $\mathbf{L}$ & $100: 0$ & $\begin{array}{l}\text { LPUJO } \\
\text { No function } R\end{array}$ & \\
\hline 42 & LHN & $\begin{array}{l}14.8 \text { um } \\
\infty \mathrm{lm}\end{array}$ & 5.2 & & $44: 56$ & $\begin{array}{l}\text { No obs L um } \\
\text { Poor function LIm }\end{array}$ & \\
\hline 43 & Bilat HN & 7.9 & 8.0 & & $16: 84$ & $\begin{array}{l}\text { Poor function } \mathrm{L} \\
\text { No obs } \mathrm{R}\end{array}$ & \\
\hline 44 & LHN & $\infty$ & $\infty$ & & $52: 48$ & No obs $L$ & \\
\hline 45 & LHN & 20.7 & 4.3 & & $46: 54$ & No obs L & LPUJO \\
\hline 46 & Bilat HN & 2.5 & 4.8 & & $51: 49$ & No obs bilat & \\
\hline 47 & R HN & 3.7 & 20.4 & & $52: 48$ & No obs $R$ & \\
\hline 48 & LHU & 6.4 & 4.3 & & $43: 57$ & No obs $L$ & \\
\hline 49 & LHN & 12.9 & 3.4 & & $51: 49$ & No obs L & \\
\hline 50 & Bilat HN & 6.5 & 5.1 & & $47: 53$ & No obs bilat & \\
\hline
\end{tabular}

1806 The Journal of NuClear Medicine • Vol. 40 - No. $11 \cdot$ November 1999 
TABLE 1 (Continued)

\begin{tabular}{|c|c|c|c|c|c|c|c|}
\hline \multirow{2}{*}{$\begin{array}{c}\text { Patient } \\
\text { no. }\end{array}$} & \multirow[b]{2}{*}{ Sonography } & \multicolumn{2}{|c|}{$\begin{array}{c}\text { Scan } \\
\text { half-time ( } \mathrm{min})\end{array}$} & \multirow{2}{*}{$\begin{array}{c}\text { Poor } \\
\text { drainage } \\
\text { with GAD }\end{array}$} & \multirow{2}{*}{$\begin{array}{l}\text { Differential } \\
\text { function } \\
\text { LR (\%) }\end{array}$} & \multirow[b]{2}{*}{ Scan result } & \multirow{2}{*}{$\begin{array}{l}\text { Final diagnosis } \\
\text { (if different } \\
\text { from scan) }\end{array}$} \\
\hline & & $\mathrm{L}$ & $\mathbf{R}$ & & & & \\
\hline 51 & LHN & $\infty$ & 3.4 & L & $54: 46$ & LPUJO & \\
\hline 52 & Bilat HN & 15.6 & 5.3 & & $47: 53$ & No obs bilat & \\
\hline 53 & LHN & 11.5 & 5.8 & & $47: 53$ & No obs L & LPUJO \\
\hline 54 & RHN & 1.3 & $\begin{array}{l}-R \text { um } \\
2.0 R \mathrm{Im}\end{array}$ & & $65: 35$ & $\begin{array}{l}\text { No function } R \text { um } \\
\text { No obs } R \mathrm{~lm}\end{array}$ & \\
\hline 55 & LHN & 9.8 & 5.1 & & $47: 53$ & No obs $L$ & \\
\hline 56 & LHN & 8.2 & 6.3 & & $47: 53$ & No obs L & \\
\hline 57 & LHN & 7.7 & - & & $100: 0$ & No obs $L$ & \\
\hline 58 & Bilat HN & $\infty$ & $\infty$ & Bilat & $51: 49$ & Bilat PUJO & \\
\hline 59 & LHN & 4.0 & 1.8 & & 43:57 & No obs L & \\
\hline 60 & LHN & 1.3 & 1.3 & & $52: 48$ & No obs $L$ & \\
\hline 61 & LHN & - & 4.2 & & $0: 100$ & No function $\mathrm{L}$ & \\
\hline 62 & R HU & 2.9 & $\infty$ & $\mathbf{R}$ & $64: 36$ & R VUJO & \\
\hline 63 & RHN & 6.2 & 25.1 & $\mathbf{R}$ & $50: 50$ & R PUJO & \\
\hline 64 & LHN & 9.4 & 6.0 & & $48: 52$ & No obs L & LPUJO \\
\hline 65 & $\mathrm{RHN}$ & 2.8 & - & & $0: 100$ & No function $\mathbf{R}$ & \\
\hline 66 & LHN & 14.8 & 6.6 & L & $54: 46$ & No obs $L$ & LPUJO \\
\hline 67 & Bilat HU & $\infty$ & $\infty$ & Bilat & $56: 44$ & Bilat VUJO & \\
\hline 68 & RHN & 4.8 & $\infty$ & $\mathbf{R}$ & & R PUJO & \\
\hline 69 & Bilat HN & 3.5 & 6.2 & & $48: 52$ & No obs bilat & \\
\hline 70 & R HN & 1.3 & - & & $100: 0$ & No function $\mathrm{R}$ & \\
\hline 71 & LHN & 7.4 & 5.1 & & 44:56 & No obs $L$ & \\
\hline 72 & R HN & 5.3 & $\infty$ & $\mathbf{R}$ & $42: 58$ & R PUJO & \\
\hline
\end{tabular}

GAD = gravity-assisted drainage; $H N=$ hydronephrosis; $\infty=$ infinity; um = upper moiety of duplex system; Im = lower moiety of duplex system; No obs = no obstruction; $\mathrm{HU}=$ hydroureteronephrosis; VUJO = vesicoureteric junction obstruction; $\mathrm{PUJO}=$ pelviureteric junction obstruction; Bilat $=$ bilateral.

ated from nonobstruction and the level of obstruction identified using this modified technique.

\section{MATERIALS AND METHODS}

Seventy-two patients (48 males, 24 females; age $2 \mathrm{~d}$ to $7 \mathrm{y}$; median age $6 \mathrm{wk}$ )with a diagnosis of hydronephrosis or hydroureteronephrosis detected on sonographic examination and who had difficulty either with venous access or with remaining still for a standard $\mathrm{F}+20$ diuretic renogram were enrolled prospectively over a 3-y period. The serum creatinine level ranged from 0.02 to 0.17 $\mathrm{mmol} / \mathrm{L}$ with a mean of $0.04 \mathrm{mmol} / \mathrm{L}$ (normal $\leq 0.05 \mathrm{mmol} / \mathrm{L}$ ). Nine patients had creatinine levels $>0.05 \mathrm{mmol} / \mathrm{L}$.

All patients had prior evaluation for vesicoureteric reflux with micturating cystourethrograms. At this institution, bladder catheterization was performed before the commencement of the study only if the child had suspected VUJ obstruction or grade II or more vesicoureteric reflux on the micturating cystourethrogram. If catheterization was required, amoxicillin or gentamicin was given because of a risk of introducing infection with the catheter. The children were orally hydrated before commencement of the study, and no volume expansion was undertaken intravenously. The degree of oral hydration was not strictly defined; infants were usually breast-fed before the study and the quantitation of milk in this situation could not be undertaken. All studies were performed on either a model $400 \mathrm{AC}$ or a model 300 gamma camera attached to a Starcam computer (General Electric Medical Systems, Milwaukee, WI) with low-energy, all-purpose collimation. The patients were studied supine and positioned so that the heart, kidneys and bladder were in the field of view. Images were obtained posteriorly. A weight-adjusted dose of ${ }^{99 \mathrm{~m}} \mathrm{Tc}-\mathrm{MAG} 3$ (using Gilday's graph [15]), with a maximum dose of $200 \mathrm{MBq}$ and minimum dose of $20 \mathrm{MBq}$, was administered intravenously, followed immediately by $1 \mathrm{mg} / \mathrm{kg}$ of furosemide (maximum dose $40 \mathrm{mg}$ ). Tissue extravasation of MAG3 or diuretic was detected either clinically with swelling at the injection site or imaging the injection site (or both). Initial dynamic images were acquired at forty 1 -s frames followed by sixty-two 20-s frames. The patients were then held upright for about $5 \mathrm{~min}$ to allow gravity-assisted drainage. Alternatively, a static image was acquired after voiding. Differential renal function was calculated using the total counts of the renogram curve for each kidney minus background counts during the interval between 1.5 and $2.5 \mathrm{~min}$ after the injection of the radiopharmaceutical. The renogram included the entire kidney and the renal pelvis. The furosemide clearance half-time was generated from the exponential fit of the maximal slope of the washout component of the renogram curve, starting at the peak of the renogram curve. Visual analysis was performed for the purpose of this study; quantitation of the counts in the regions of interest of the kidneys before and after gravity-assisted drainage will be addressed elsewhere.

To differentiate between obstruction and nonobstruction, the diagnoses were determined on the following criteria:

Significant PUJ obstruction was diagnosed if (a) visual analysis showed no significant drainage or progressive accumulation of radiopharmaceutical in the renal pelvicalyceal system, or furose- 
mide clearance half-time $>20 \mathrm{~min}$, and (b) visual comparison of before and after gravity-assisted drainage images showed no significant change.

Significant VUJ obstruction was diagnosed if (a) visual analysis showed no significant drainage or progressive accumulation of radiopharmaceutical in the ureter, or furosemide clearance halftime $>20 \mathrm{~min}$, and (b) visual comparison of before and after gravity-assisted drainage images showed no significant change.

An obstructed renal unit (defined as a kidney and its ureter) was also diagnosed if there was poor, i.e., $<20 \%$, relative function or no function in the renal unit in the presence of hydronephrosis or hydroureteronephrosis on sonographic examination.

A not significantly obstructed (referred to as nonobstructed) renal unit was diagnosed if (a) visual analysis showed good drainage of the renal pelviureteric system, or furosemide clearance half-time $<20 \mathrm{~min}$, and (b) visual comparison of before and after gravity-assisted drainage images showed significant further drainage.

A not significantly obstructed (referred to as nonobstructed) renal unit was also diagnosed even if the visual analysis showed no significant drainage or progressive accumulation of radiopharmaceutical in the renal pelvicalyceal system or ureter, or furosemide clearance half-time $>\mathbf{2 0} \mathrm{min}$, as long as the visual comparison of the before and after gravity-assisted drainage images showed significant further drainage.

All patients were followed-up for 6-12 mo, and the results of the $\mathrm{F}+0$ diuresis renography were compared with the final diagnoses. All patients had clinical follow-up at 3-mo intervals with sonographic examinations performed at intervals of 3-6 mo. Repeated diuresis renography was performed if there was increasing dilatation found on the sonographic study. The final diagnoses were based on either surgical findings or conservative management with repeated sonography and ${ }^{99 m}$ Tc-MAG3 examinations. The decision for surgical intervention or conservative management was determined by the pediatric urologist, who considered the results of the diuresis renography, including the relative function of the kidney, the child's clinical findings and serial sonographic examination appearances before making the management decision.

\section{RESULTS}

The patients' data and results are shown in Table 1. A renal unit was defined as a kidney and its ureter. Of the 72 patients, there were 151 renal units for data analysis because 1 patient (patient 23) had bilateral duplex kidneys, 6 patients (patients $1,26,31,35,42$ and 54) had unilateral duplex kidneys and 1 patient (patient 57) had a solitary kidney. One patient (patient 41) had a horseshoe kidney.

There were 53 normal nondilated renal units on sonographic examination, all showing good diuretic responses on $\mathrm{F}+0$ diuresis renography with furosemide clearance halftimes of 1.3-6.3 min (mean $3.8 \mathrm{~min}$ ). In addition, 9 patients (patients 5, 10, 11, 17, 22, 24, 31, 40 and 58) had creatinine levels of $0.06-0.17 \mathrm{mmol} / \mathrm{L}$, and differentiation of renal obstruction from nonobstruction was achieved in this group except for patient 11 . The nondilated renal units in this group with elevated creatinine levels had a furosemide clearance half-time of 2.3-5.3 min (mean 4.1 min).

Except for the renal units with no or poor function, the level of obstruction was determined by visual analysis of the
TABLE 2

Results of 96 Abnormal Renal Units

\begin{tabular}{|c|c|c|c|}
\hline \multicolumn{2}{|c|}{$\mathrm{F}+0$ diuresis study } & \multicolumn{2}{|c|}{$\begin{array}{l}\text { Final diagnosis } \\
\text { (if different } \\
\text { from scan) }\end{array}$} \\
\hline Result & No. & Result & No. \\
\hline $\begin{array}{l}\text { Nonobstruction } \\
\text { Total nonobstruction } \\
\text { Obstruction } \\
\text { Poor function } \\
\text { No function } \\
\text { Total obstruction }\end{array}$ & $\begin{array}{r}\frac{53}{53} \\
27 \\
4 \\
\frac{12}{43}\end{array}$ & $\begin{array}{l}\text { Obstruction } \\
\text { Nonobstruction }\end{array}$ & 3 \\
\hline Sensitivity = $88.9 \%$ & ficity & $.4 \% ;$ accuracy $=$ & $\%$. \\
\hline
\end{tabular}

diuresis renography studies as outlined in Table 1. The results of the abnormal renal units are summarized in Table 2. Ninety-six renal units had hydronephrosis or hydroureteronephrosis on sonography and were investigated for renal obstruction using $\mathrm{F}+0$ diuresis renography. After the $\mathrm{F}+0$ study, 53 of these renal units were further classified as nonobstructed and 43 were classified as obstructed.

Fifty-three renal units classified as nonobstructed, with 48 renal units showing no obstruction on the subsequent 12-mo follow-up. There were five false-negative studies with surgery revealing typical PUJ obstruction on 4 renal units (patients 36, 45, 53 and 66). Two patients (patients 36 and 45) had increasing pelvicalyceal dilatation on follow-up sonographic examinations; 2 other patients (patients 53 and 66) had worsening sonographic appearances, and subsequent F+20 diuresis renography studies revealed PUJ obstruction. Intermittent left loin pain developed in patient 64 and he was found to have anomalous lower pole vessels at surgery, most likely causing intermittent ureteric obstruction. The ages of the 5 patients with false-negative studies varied, ranging from 8 wk to $5.5 \mathrm{y}$.

Of the renal units classified as obstructed, there were 4 renal units (patients 1,31, 42 and 43) with poor renal function, 12 renal units (patients $5,7,9,10,26,35,38,41$, $54,61,65$ and 70) with no renal function, and 27 renal units with obstruction. Of the 4 renal units with poor function, patient 1 had a right upper pole nephrectomy for a VUJ obstruction associated with a large ureterocele at the right side of the trigone, and patient 42 had a left lower pole pyeloplasty for a grossly dilated lower pole component with a tight PUJ obstruction. Patients 31 and 43 had pyeloplasties for tight PUJ obstruction.

For 5 of the 12 obstructed renal units with no function, patients 5, 7, 61, 65 and 70 (5 renal units) had nephrectomies for hydronephrotic dysplastic kidneys with features associated with a tight PUJ obstruction. Patient 54 (one renal unit) had upper pole partial nephrectomy for a nonfunctioning obstructed right upper pole moiety. Patients 9 and 35 (two renal units) had left nephrectomy, left ureterectomy and excision of associated ureterocele and left upper pole 
nephrectomy, left ureterectomy and excision of ureterocele, respectively, for VUJ obstruction. Patients 10, 26 and 38 (three renal units) had left nephrectomy, left lower pole partial nephrectomy and right nephrectomy, respectively, for nonfunction associated with renal dysplasia, which was diagnosed histologically after resection. Patient 41 (one renal unit) had a nonfunctioning component of a horseshoe kidney. Figure 1 shows a nonfunctioning lower pole moiety of the duplex left kidney associated with a severe PUJ obstruction confirmed surgically.

The remaining 27 renal units classified as obstructed had 19 renal units (patients 8, 12, 14, 19, 21, 22, 25, 27, 30, 41, $51,58,63,68$ and 72) with PUJ obstruction and 8 renal units (patients 2, 6, 11, 29, 37, 62 and 67) with VUJ obstruction. Figure 2 illustrates a case of unilateral PUJ obstruction, and Figure 3 shows a case of bilateral VUJ obstruction. At surgery, obstruction of 24 of these renal units (patients 2, 6, $12,14,19,22,25,27,29,30,37,41,51,58,63,67,68$ and 72) was confirmed with either pyeloplasties or reduction ureteroplasties and ureteric reimplantation performed. All 18 renal units (patients $8,12,14,19,22,25,27,30,41,51,58$, 63, 68 and 72) with PUJ obstruction and 6 renal units (patients 2, 6, 37, 62 and 67) with VUJ obstruction were correctly identified as to the level of obstruction on diuresis renography compared with the results of the surgery.

There were 3 false-positive studies with 3 renal units (patients 11, 21 and 29) showing no obstruction on follow-up sonography and $99 \mathrm{~m}$ Tc-MAG3 examinations. Two of these renal units (patients 11 and 29) were diagnosed on the $\mathrm{F}+0$ diuresis renography study as having VUJ obstruction, and 1 renal unit (patient 21) was diagnosed as having PUJ obstruction. These 3 patients remained clinically well in the 12-mo follow-up period with improving appearances on sonography and ${ }^{99 m}$ Tc-MAG3 studies. Two of these patients (patients 21 and 29) were 6 wk old and the other (patient 11) was 9 mo old.

On the basis of the $\mathrm{F}+\mathbf{0}$ diuresis renography study and the final diagnoses based on either surgery or conservative management with follow-up sonography and ${ }^{99 m}$ Tc-MAG3

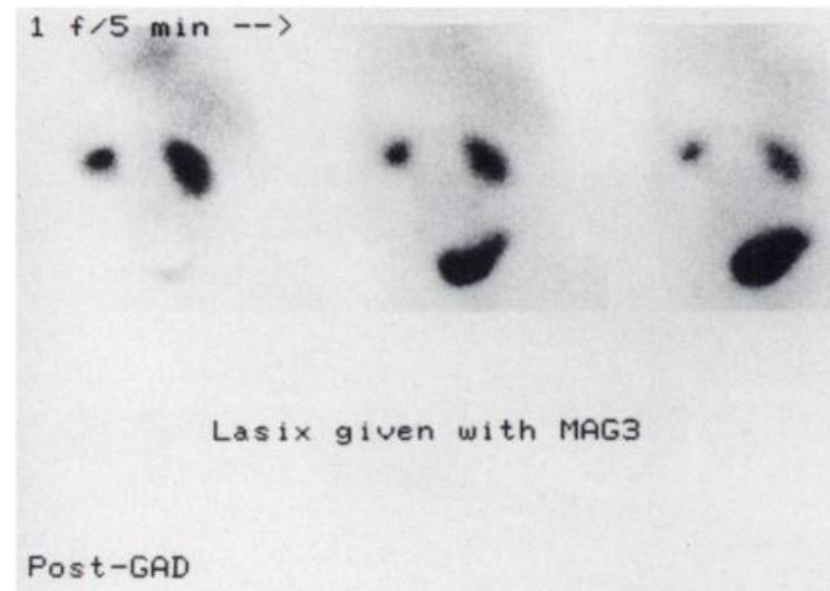

studies, the sensitivity of the study was $88.9 \%$, specificity was $94.1 \%$ and accuracy was $91.7 \%$.

\section{DISCUSSION}

$\mathbf{F}+\mathbf{0}$ diuresis renography is a term recently used by O'Reilly et al. (11). Some departments use the F+0 diuresis renography method (11), but there is a paucity of literature validating this method (12).

It is difficult to provide a gold standard for the $\mathrm{F}+0$ diuresis renography study. However, we believe that follow-up data of up to 12 mo to ascertain whether the patients require surgery with the subsequent operative findings or conservative management is a valid way of justifying the feasibility of the F+0 diuresis renography study. A 3- to 6-mo observation period for neonates with hydronephrosis associated with PUJ anomalies when definite obstruction cannot be confirmed by diuresis renography has been recommended $(2,10)$. The pediatric urologist takes into account not only diuresis renography studies but also other parameters such as the relative function of the kidney, the child's clinical presentation and sonographic examination findings before embarking on surgical intervention.

In the neonatal group, the operative findings that cause the obstruction vary. Some children have classic fibromuscular hyperplasia at the PUJ. Other children appear to have proximal ureters with a corkscrew appearance that may result in obstruction at the PUJ caused by kinking of the ureter at the site of tortuosity. Another group has lower pole vessels that compress the renal pelvis and result in intermittent PUJ obstruction. Causes of VUJ obstruction include adynamic nonperistaltic tonically contracted distal ureteral segments and ureteroceles.

Another justification of the $\mathrm{F}+0$ diuresis renography method is that the $\mathbf{5 3}$ normal nondilated renal units all had a furosemide clearance half-time of $<10 \mathrm{~min}$, which is the normal or nonobstructed range reported in the literature $(17,18)$. In addition, 9 patients had creatinine levels between 0.06 and $0.17 \mathrm{mmol} / \mathrm{L}$, and results of the $\mathrm{F}+0$ study were still interpretable with the nondilated renal units all having a 
$1 f / 5 \min -->$

FIGURE 2. Left PUJ obstruction. Posterior views show radiopharmaceutical in dilated left pelvicalyceal system, which drained poorly and remained essentially unchanged after gravity-assisted drainage (Post-GAD). (Furosemide [Lasix; Hoechst-Roussel Pharmaceuticals, Inc., Somerville, NJ] was given with mercaptoacetyltriglycine [MAG3].) Furosemide clearance half-time was infinity for left kidney and 3.4 min for right kidney. Tight PUJ obstruction was found at surgery.
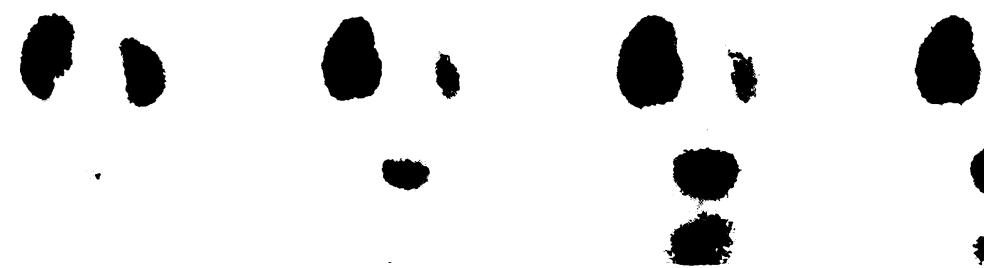

\section{Lasix given with MAG3}

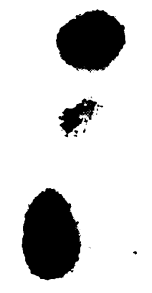

Post-GAD

normal furosemide clearance half-time of $<10 \mathrm{~min}$. However, the number of patients is small, and caution should be undertaken when interpreting renography results in patients with severe renal impairment.

Five renal units were considered false-negative studies for the purpose of this investigation; on follow-up, the patients underwent surgical exploration and were found to have PUJ obstruction. The phenomenon of transitional hydronephrosis has been postulated, in which progressive maturation may result in either progression or resolution of the obstruction $(16,19-21)$ or intermittent hydronephrosis, which can be disabling (22). False-negative studies may also be associated with partial obstruction (23). Follow-up is recommended for patients with a nonobstructed appearance because falsenegative studies and obstruction may also develop with time $(16,21,22-24)$.

Three renal units were considered false-positive studies for the purpose of this investigation; the patients were classified as having significant obstruction but were managed expectantly because of good relative renal function and improving sonographic and ${ }^{99 \mathrm{~m}} \mathrm{Tc}-\mathrm{MAG} 3$ findings. In this subgroup of patients, spontaneous improvement in drainage occurred on follow-up assessment. False-positive diuretic renography studies have included patients with a poorly functioning kidney and patients in whom there is a very large dilated collecting system.

The duration of the $\mathrm{F}+0$ diuresis renography study is 25 min, i.e., $20 \mathrm{~min}$ for the diuretic phase, followed by the 5-min gravity-assisted drainage or imaging after voiding. The need for an additional view after gravity-assisted drainage in diuresis renography has been emphasized (25). The traditional $\mathrm{F}+20$ diuresis renography study takes approximately $45 \mathrm{~min}$ to acquire $(9-11)$. Therefore, the F+0 study is a shorter study.

Because the radiopharmaceutical and diuretic are administered together in a single intravenous injection, the $\mathrm{F}+0$ diuresis renography study is also less invasive compared with the $\mathrm{F}+20$ study, which requires two separate injections within $20 \mathrm{~min}(9-11)$.

All normal nondilated renal units on sonographic examinations showed a good diuretic response with a furosemide clearance half-time well below $10 \mathrm{~min}$, which is the accepted normal range (17). Together with the sensitivity, specificity and accuracy obtained for the $\mathrm{F}+0$ diuresis renography study, we believe that this is a valid method for the investigation of hydronephrosis and hydroureteronephrosis in infants and children.
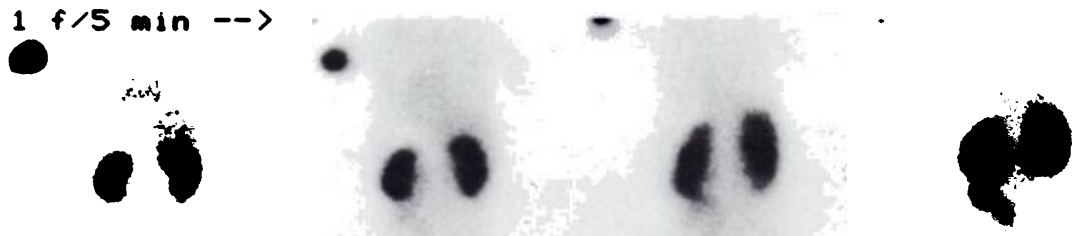

FIGURE 3. Bilateral VUJ obstruction. Posterior views show significant accumulation of radiopharmaceutical in both pelviureteric systems with poor drainage after gravityassisted drainage (Post-GAD). Furosemide clearance half-time was infinity for both kidneys. Bilateral ureterostomies were performed to relieve obstruction.

Post-GAD
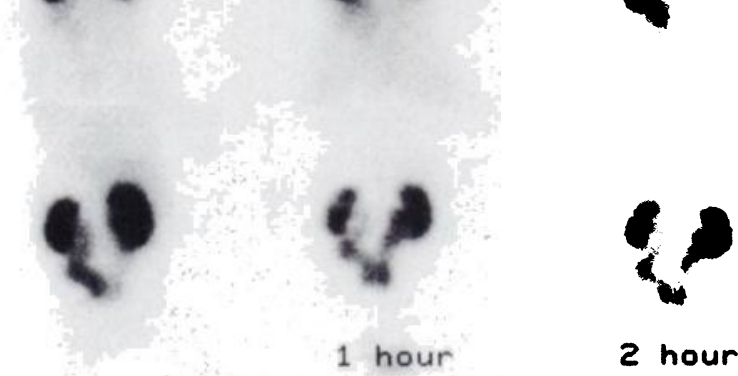

2 hours 


\section{CONCLUSION}

In the $\mathrm{F}+0$ diuresis renography study of infants and children, good diuretic responses are shown in normal kidneys; the data and results justify the usefulness of this method in the investigation of hydronephrosis and hydroureteronephrosis to differentiate between renal obstruction and nonobstruction. The level of the obstruction is also correctly identified in cases in which there is good renal function. In addition, the $\mathrm{F}+0$ diuresis renography study has a shorter imaging time and is less invasive compared with the traditional $\mathrm{F}+20$ study.

\section{REFERENCES}

1. Diamond DA, Gosalbez R. Neonatal urologic emergencies. In: Walsh PC, Retik AB, Vaughan ED, Wein AJ, eds. Campbell's Urology. 7th ed. Philadelphia, PA: WB Saunders; 1998:1629-1654.

2. Heyman S. Radionuclide studies of the genitourinary tract. In: Miller JH, Gelfand MJ, eds. Pediatric Nuclear Imaging. Philadelphia, PA: WB Saunders; 1994:195252.

3. Gordon I. Paediatric uroradiology. In: Grainger RG, Allison DJ, eds. Diagnostic Radiology. 2nd ed. Edinburgh, Scotland: Churchill Livingstone; 1992:1379 1416.

4. Gordon I. Paediatric aspects of radionuclides in nephrourology. In: Murray IPC, Ell PJ, eds. Nuclear Medicine in Clinical Diagnosis and Treatment. Edinburgh, Scotland: Churchill Livingstone; 1994:259-270.

5. Chung S, Majd M, Rushton HG, Belman AB. Diuretic renography in the evaluation of neonatal hydronephrosis: is it reliable? J Urol. 1993;150:765-768.

6. Wong JCH, Rossleigh MA, Farnsworth RH. Utility of technetium-99m-MAG3 diuretic renography in the neonatal period. J Nucl Med. 1995;36:2214-2219.

7. Choong KKL, Gruenewald SM, Hodson EM, Antico VF, Farlow DC, Cohen RC Volume expanded diuretic renography in the postnatal assessment of suspected uretero-pelvic junction obstruction. J Nucl Med. 1992;33:2094-2098.

8. Jamar F, Piret L, Wese F, Beckers C. Influence of ureteral status on kidney washout during technetium-99m-DTPA diuresis renography in children. $J$ Nucl Med. 1992;33:73-78.

9. Society for Fetal Urology and Pediatric Nuclear Medicine Council - The Society of Nuclear Medicine. The "well tempered" diuretic renogram: a standard method to examine the asymptomatic neonate with hydronephrosis or hydroureteronephrosis. J Nucl Med. 1992;33:2047-2051.
10. Conway JJ. "Well-tempered" diuresis renography: its historical development, physiological and technical pitfalls, and standardized technique protocol. Semin Nucl Med. 1992;22:74-84.

11. O'Reilly P, Aurell A, Britton K, Kletter K, Rosenthal L, Testa T. Consensus on diuresis renography for investigating the dilated upper urinary tract. $\mathrm{J} \mathrm{Nucl} \mathrm{Med}$. 1996;37:1872-1876.

12. O'Reilly PH. Standardization of diuresis renography techniques [editorial]. Nucl Med Commun. 118;19:1-2.

13. Sfakianakis GN, Heiba S, Ganz W, et al. Diuretic renography with early injection of furosemide: a reliable and cost effective approach [abstract]. J Nucl Med. 1989;30:841.

14. Boubaker A, Meyrat B, Frey P, Bezy MF, Muller C, Bischof-Delaloye A. Diuresis renography with early $\left(2-3^{\prime}\right)$ frusemide injection [abstract]. Eur J Nucl Med. 1997;24:866.

15. Goetz WA, Hendee WR, Gilday DL. In vivo diagnostic nuclear medicine: pediatric experience. Clin Nucl Med. 1983;8:434-439.

16. Homsy YL, Williot P, Danais S. Transitional neonatal hydronephrosis: fact or fantasy? J Urol. 1986;136:339-341.

17. Rossleigh MA, Thomas MY, Moase AL. Determination of the normal range of furosemide half-clearance times when using Tc-99m MAG3. Clin Nucl Med. 1994;19:880-882.

18. Brown SCW. Nuclear medicine in the clinical diagnosis and treatment of obstructive uropathy. In: Murray IPC, Ell PJ, eds. Nuclear Medicine in Clinical Diagnosis and Treatment. Edinburgh, Scotland: Churchill Livingstone; 1994:271294.

19. Gordon I, Dhillon HK, Peters AM. Antenatal diagnosis of renal pelvic dilatation: the natural history of conservative management. Pediatr Radiol. 1991;21:272273.

20. Ransley PG, Dhillon HK, Gordon I, Duffy PG, Dillon MJ, Barratt TM. The postnatal management of hydronephrosis diagnosed by prenatal ultrasound. $J$ Urol. 1990;144:584-587.

21. Homsy YL, Saad F, Laberge I, Williot P, Pison C. Transitional hydronephrosis of the newborn and infant. $J$ Urol. 1990;144:579-583.

22. Homsy YL, Mehta PH, Huot D, Danais S. Intermittent hydronephrosis: a diagnostic challenge. J Urol. 1988;140:1222-1226.

23. McBiles M, Lambert AT, Cote MG, Solano RK. Diuretic scintirenogram: past, present, and future. In: Freeman LM, ed. Nuclear Medicine Annual 1995. New York, NY: Raven Press; 1995:185-216.

24. Koff SA. Neonatal management of unilateral hydronephrosis: role for delayed intervention. Urol Clin North Am. 1998;25:181-186.

25. Rossleigh MA, Leighton DM, Farnsworth RH. Diuresis renography: the need for an additional view after gravity-assisted drainage. Clin Nucl Med. 1993;18:210 213. 